\title{
Gold anion catalysis of methane to methanol
}

\author{
Alfred Z. Msezane • Zineb Felfli • Kelvin Suggs • \\ Aron Tesfamichael $\cdot$ Xiao-Qian Wang
}

Published online: 3 July 2012

(C) The Author(s) 2012. This article is published with open access at Springerlink.com

\begin{abstract}
The oxidation of $\mathrm{CH}_{4}$ has been investigated in the presence and absence of the atomic $\mathrm{Au}^{-}$ion catalyst. We have employed the first principles density functional theory (DFT) and dispersion-corrected DFT calculations for the transition state on the $\mathrm{Au}^{-}$ion and analyzed the thermodynamics properties of the reactions as well. Our results demonstrate that atomic gold anions could be used to catalyze $\mathrm{CH}_{4}$ into valuable industrial products without the emission of $\mathrm{CO}_{2}$, thereby making gold extremely valuable. The fundamental mechanism involves breaking the $\mathrm{C}-\mathrm{H}$ bond through the formation of the anionic $\mathrm{Au}^{-}\left(\mathrm{CH}_{4}\right)$ molecular complex permitting the oxidation of $\mathrm{CH}_{4}$ to methanol at the temperature of $325 \mathrm{~K}$ which is below that of $\mathrm{CO}_{2}$ emission. Potentially, this could significantly impact the quality of our environment.
\end{abstract}

\subsection{0. $+\mathrm{x} \cdot 31.15 . \mathrm{es} \cdot 34.50 . \mathrm{Lf}$}

\section{Introduction}

Nowadays, considerable efforts continue to be devoted to finding ways to reduce $\mathrm{CO}_{2}$ emissions and atmospheric

Electronic supplementary material The online version of this article (doi:10.1007/s13404-012-0056-7) contains supplementary material, which is available to authorized users.

A. Z. Msezane $\cdot$ Z. Felfli $(\varangle) \cdot$ X.-Q. Wang

Department of Physics and Center for Theoretical Studies

of Physical Systems, Clark Atlanta University,

Atlanta, GA 30314, USA

e-mail: zfelfli@cau.edu

K. Suggs $\cdot$ A. Tesfamichael

Department of Chemistry, Clark Atlanta University,

Atlanta, GA 30314, USA concentrations. Carbon sequestration, improving the efficiency of energy use, and reducing the carbon content of fuels are three major pathways that are currently being pursued to address the stabilization of greenhouse gas concentrations [1]. Carbon sequestration uses various approaches for $\mathrm{CO}_{2}$ capture, storage, and reuse [1,2]. One such process, $\mathrm{CO}_{2}$ mineralization, uses carbonic anhydrase enzyme to convert dilute, unseparated $\mathrm{CO}_{2}$ to $\mathrm{HCO}_{3}$ and finally to everlasting calcium and magnesium carbonates. Biogenic methane is another of the carbon sequestrations; it involves geologic storage of $\mathrm{CO}_{2}$ in depleting and depleted oil and gas reservoirs, with subsequent conversion of the $\mathrm{CO}_{2}$ to $\mathrm{CH}_{4}$ via designer microbes or biomimetic systems that operate above or below ground [1]. Common among many of these concepts is the enhancement of naturally occurring biochemical and geochemical processes through the identification and replication of natural processes for the purposes of carbon sequestration.

The catalytic partial oxidation of methane into valuable products is of great scientific importance and considerable industrial, economic, and environmental interest. However, a great challenge is that in the absence of an appropriate catalyst, methane undergoes complete combustion yielding carbon dioxide and water at approximately $340 \mathrm{~K}$ with minimal competition with the formation of useful products that can occur at elevated temperatures. The fundamental ideas of muon-catalyzed nuclear fusion utilizing a negative muon, a deuteron, and a triton [3] are used in the proposed oxidation of $\mathrm{CH}_{4}$ to methanol for which we have selected the atomic gold anion as the catalyst. Here we propose the use of the atomic $\mathrm{Au}^{-}$ion catalyst to control the temperature of the oxidation of methane to methanol around $325 \mathrm{~K}$. This has the effect of lowering the transition state (TS) by $32 \%$ compared to the case of the absence of the catalyst for the complete oxidation of methane to methanol without carbon 
dioxide emission. We have employed the first principles density functional theory (DFT) and dispersion-corrected DFT calculations for the transition state on the $\mathrm{Au}^{-}$ion and analyzed the thermodynamics properties of the reactions as well.

The main motivations for the investigation are: (1) the direct synthesis of $\mathrm{H}_{2} \mathrm{O}_{2}$ from $\mathrm{H}_{2}$ and $\mathrm{O}_{2}$ using supported $\mathrm{Au}, \mathrm{Pd}$, and $\mathrm{Au}-\mathrm{Pd}$ nanoparticle catalysts $[4,5]$ including the theory $[6,7]$ that attributed the catalytic properties of $\mathrm{Au}$ and Pd to the formation of negative ion resonances in lowenergy electron elastic total cross sections (TCSs) for $\mathrm{Au}$ and Pd atoms, along with their large electron affinities (EAs); (2) the recent dispersion-corrected density functional theory transition-state calculations performed on the atomic $\mathrm{Au}^{-}$ion catalysis of water conversion to $\mathrm{H}_{2} \mathrm{O}_{2}$, revealing that the formation of the $\mathrm{Au}^{-}\left(\mathrm{H}_{2} \mathrm{O}\right)_{2}$ anion molecular complex in the transition state provides the fundamental mechanism for breaking up the hydrogen bonding strength in the catalysis of $\mathrm{H}_{2} \mathrm{O}_{2}$ using the $\mathrm{Au}^{-}$ion [8]. It is important to note that the $\mathrm{Au}^{-}$ion is employed here as a prototype for negatively charged gold clusters or surfaces. The peculiar binding energy associated with the $\mathrm{Au}^{-}$ion is of fundamental distinction as compared to that of the $\mathrm{Au}^{+}$ion or the neutral $\mathrm{Au}$ atom

Contrary to bulk gold, nanogold exhibits surprisingly high activity and/or selectivity in the combustion as well as partial oxidation of various molecules and compounds [9]. Since the publication of the paper [9], there have been considerable research activities on nanogold, particularly on its catalytic properties [9-29]. The mechanisms of charge transfer [11, 12] and relativity [13] have been advanced as possible explanations for the excellent catalytic properties of gold nanoparticles. Recently, the negative ion resonances that characterize the electron elastic scattering TCSs for atomic Au have been proposed as the fundamental mechanism driving nanoscale catalysis [6, 7]. The catalytic combustion of methane, the main component of natural gas, including its conversion to useful products, has recently received extensive experimental and theoretical attention because of the potential to reduce pollutant emissions and synthesize useful chemicals [30-36] and references therein. A recent investigation demonstrated the selective conversion of a mixture of methane and oxygen to formaldehyde at temperatures below $250 \mathrm{~K}$ through temperature-controlled $\mathrm{Au}^{2+}$ nanocatalysis [36].

Experimentally, it has been established that the $\mathrm{Au}^{-}$anion interacts with water molecules to form the $\mathrm{Au}^{-}\left(\mathrm{H}_{2} \mathrm{O}\right)_{1,2}$ complexes, causing bond breaking and with methane to form the $\mathrm{Au}^{-}\left(\mathrm{CH}_{4}\right)$ complex [37], thereby weakening the $\mathrm{C}-\mathrm{H}$ bond. Furthermore, the strong interaction between the $\mathrm{Au}^{-}$anion and $\mathrm{H}_{2} \mathrm{O}$ is comparable to the hydrogen bonding in $\mathrm{H}_{2} \mathrm{O}$ and the $\mathrm{Au}^{-}$anion interaction with $\mathrm{CH}_{4}$ is significant as well, but the $\mathrm{Au}^{-}$ion does not interact with $\mathrm{O}_{2}$ [29].
These findings $[29,37]$ are vital to the fundamental understanding of nanocatalysis using $\mathrm{Au}$ nanoparticles. To our knowledge, our proposed approach is the first to use the $\mathrm{Au}^{-}$ negative ion in the catalytic combustion of methane to useful products without the emission of $\mathrm{CO}_{2}$.

\section{Reactions and calculation method}

The complete combustion of methane leads to the formation of carbon dioxide and water:

$\mathrm{CH}_{4}+2 \mathrm{O}_{2} \rightarrow \mathrm{CO}_{2}+2 \mathrm{H}_{2} \mathrm{O}$

Possible by-products of the partial oxidation of methane are:

$\mathrm{CH}_{4}+\frac{1}{2} \mathrm{O}_{2} \rightarrow \mathrm{CO}+2 \mathrm{H}_{2}$

$\mathrm{CH}_{4}+\frac{1}{2} \mathrm{O}_{2} \rightarrow \mathrm{CH}_{3} \mathrm{OH}$

$\mathrm{CH}_{4}+\mathrm{O}_{2} \rightarrow \mathrm{H}_{2} \mathrm{CO}+\mathrm{H}_{2} \mathrm{O}$

$\mathrm{CH}_{4}+\mathrm{O}_{2} \rightarrow \mathrm{HCO}_{2} \mathrm{H}+\mathrm{H}_{2}$

Generally, there is little competition between the complete oxidation, reaction (1) and the selective partial oxidation (SPO), reactions $(2,3,4$, and 5), of methane. There are two reasons why the overall reaction leads to the formation of carbon dioxide and water: (1) Complete combustion of methane occurs at the lowest temperature compared to its SPO and (2) the corresponding transition state for reaction (1) is lowest compared to that of any SPO of methane to the desired products. However, the atomic $\mathrm{Au}^{-}$negative ion activates molecular oxygen in $\mathrm{CH}_{4}$ and increases the level of the SPO of methane to produce useful compounds.

Here the atomic $\mathrm{Au}^{-}$catalyst is used to control the oxidation temperature of methane around $325 \mathrm{~K}$ to lower the transition state by $32 \%$ compared to the case of the absence of the catalyst for the complete oxidation of methane to methanol and further oxidize methanol to formaldehyde and formic acid without $\mathrm{CO}_{2}$ emission. We follow exactly the same procedure as in $[6,7]$ when applying the atomic $\mathrm{Au}^{-}$ion catalyst to each of the reactions $(1,2,3,4$, and 5).

The proposed mechanism of catalysis using the negative $\mathrm{Au}^{-}$ion catalyst is as follows. When a slow electron collides elastically with a ground-state neutral gold atom, attachment can result, leading to the formation of a negative ion resonance due to the formation of compound atomic states. The 
energy position of this negative ion resonance corresponds to the stable bound state of the $\mathrm{Au}^{-}$negative ion formed during the collision as a resonance. The binding energy of the $\mathrm{Au}^{-}$ion defines the EA of atomic Au. Theoretically, it has been demonstrated that the EA of $\mathrm{Au}$ is right at the absolute minimum or the second R-T minimum (absolute) of the elastic TCS of $\mathrm{Au}[6,7,38,39]$. At this minimum and within the appropriate environment, the attachment of the $\mathrm{Au}^{-}$negative ion to the $\mathrm{CH}_{4}$ molecule results in the formation of the $\mathrm{Au}^{-}\left(\mathrm{CH}_{4}\right)$ anionic molecular complex. This complex formation results in the disruption of the stable $\mathrm{C}-\mathrm{H}$ bonds in the methane molecule. The attendant change in the Gibbs energy of the system becomes negative, thereby thermodynamically favoring the formation of methanol. The $\mathrm{Au}^{-}$ion is released after the chemical reaction. We note that the dissociative energy of the $\mathrm{Au}^{-}\left(\mathrm{CH}_{4}\right)$ molecular complex is within the second R-T minimum of the Au elastic TCS.

We have employed the first principles calculations based on DFT and dispersion-corrected DFT approaches for the investigation. For geometry optimization of structural molecular confirmation, we utilized the gradient-corrected Perdew-Burke-Ernzerfof parameterizations [40] of the exchange correlation rectified with the dispersion corrections [41]. The double numerical plus polarization basis set was employed as implemented in the DMol3 package [42]. The dispersion correction method, coupled to suitable density functional, has been demonstrated to account for the long-range dispersion forces with remarkable accuracy. We used a tolerance of $1.0 \times 10^{-3} \mathrm{eV}$ for energy convergence. A transition-state search employing nudged elastic bands facilitates the evaluation of energy barriers [43-45]. Finally, the energy of the transition state was calculated and the thermodynamic properties of the reaction were analyzed from the DMol3 package [42]. As the calculation of the transition barrier depends crucially on the exchange correlation scheme employed, the use of reliable dispersion-corrected approach is essential. The error in extracting the transition barrier associated with the transition pathway was estimated to be less than $0.001 \mathrm{eV}$ [43-45].

\section{Results and discussion}

Figures 1, 2, 3, 4, and 5 present the optimized structures of the reactants, transition states, and products of oxidation of methane leading to the formation of $\mathrm{CO}_{2}, \mathrm{CO}, \mathrm{CH}_{3} \mathrm{OH}$, $\mathrm{H}_{2} \mathrm{CO}$, and $\mathrm{HCO}_{2} \mathrm{H}$, respectively. The data in (a) correspond to the absence of the $\mathrm{Au}^{-}$ion catalyst while those in (b) are data when the $\mathrm{Au}^{-}$ion catalyst is present. The red, white, gray, and gold spheres represent respectively oxygen, hydrogen, carbon, and gold atoms. The TS and EP, both in electron volts, represent respectively the calculated transition-state energy and the energy of the products. The breaking of the stable $\mathrm{C}-\mathrm{H}$ bonds in the methane molecule in the transition state resulting in the formation of methanol in the presence of $\mathrm{O}_{2}$ is attributed to the formation of the anionic $\mathrm{Au}^{-}\left(\mathrm{CH}_{4}\right)$ complex. The role of the $\mathrm{Au}^{-}$ion is to disrupt the stable $\mathrm{C}-\mathrm{H}$ bonds in the methane molecule, allowing the formation of methanol in the presence of $\mathrm{O}_{2}$. It is noted that the optimized structure corresponding to the reaction (3), namely the production of methanol, has the lowest transition-state energy (see Figs. 1b, 2b, 3b, 4b, and $5 b)$. These results are also summarized in Table 1.

Understanding the results

Here we discuss the results of the complete oxidation of $\mathrm{CH}_{4}$, reaction (1), and of the SPO of $\mathrm{CH}_{4}$, reaction (3) as illustrations; the latter analysis also applies to the remaining reactions. In $[6,7]$ we explained the catalytic production of $\mathrm{H}_{2} \mathrm{O}_{2}$ from $\mathrm{H}_{2} \mathrm{O}$, using the atomic $\mathrm{Au}^{-}$ion catalyst, in the presence of $\mathrm{O}_{2}$. Similarly, here we first apply the atomic $\mathrm{Au}^{-}$ ion catalyst to the complete oxidation of $\mathrm{CH}_{4}$, reaction (1), and obtain:

$\mathrm{Au}^{-}\left(\mathrm{CH}_{4}\right)+2 \mathrm{O}_{2} \rightarrow \mathrm{Au}^{-}+2 \mathrm{H}_{2} \mathrm{O}_{2}+\mathrm{CO}_{2}$

$\mathrm{Au}^{-}+2 \mathrm{CH}_{4}+2 \mathrm{O}_{2} \rightarrow \mathrm{Au}^{-}\left(\mathrm{CH}_{4}\right)+2 \mathrm{H}_{2} \mathrm{O}_{2}+\mathrm{CO}_{2}$

Adding the reactions (8) and (9), we get:

$\mathrm{CH}_{4}+2 \mathrm{O}_{2} \rightarrow 2 \mathrm{H}_{2} \mathrm{O}+\mathrm{CO}_{2}$

The $\mathrm{Au}^{-}$ion catalyst has changed nothing in the reaction, demonstrating complete combustion. The results of Table 1 (same TS values for the absence and presence of the catalyst) and Figs. 1 and 7 are illustrations of the complete combustion process. We note that the purpose of a catalyst is to decrease the reaction temperature to ambient temperature [46]. So, the $\mathrm{Au}^{-}$catalyst cannot be effective since the $340 \mathrm{~K}$ temperature (Table 1 ) is the ambient temperature for $\mathrm{CO}_{2}$ production.

Next we apply the $\mathrm{Au}^{-}$ion catalyst to the reaction (3) and obtain:

$\mathrm{Au}^{-}\left(\mathrm{CH}_{4}\right)+1 / 2 \mathrm{O}_{2} \rightarrow \mathrm{Au}^{-}+\mathrm{CH}_{3} \mathrm{OH}$

$\mathrm{Au}^{-}+2 \mathrm{CH}_{4}+1 / 2 \mathrm{O}_{2} \rightarrow \mathrm{Au}^{-}\left(\mathrm{CH}_{4}\right)+\mathrm{CH}_{3} \mathrm{OH}$

Adding the reactions (9) and (10), we have:

$\mathrm{CH}_{4}+1 / 2 \mathrm{O}_{2} \rightarrow \mathrm{CH}_{3} \mathrm{OH}$

Contrary to the complete oxidation of methane, reaction (1), the $\mathrm{Au}^{-}$ion catalyzes the SPO of $\mathrm{CH}_{4}$ to a new product, namely $\mathrm{CH}_{3} \mathrm{OH}$ without $\mathrm{CO}_{2}$ emission, reaction (11). As seen from comparing the TSs in column 2 and column 5 of 
Fig. 1 Complete oxidation of methane to carbon dioxide and water in the absence (a) and presence (b) of the $\mathrm{Au}^{-}$ negative ion catalyst. The red, white, gray, and gold spheres represent respectively oxygen, hydrogen, carbon, and gold atoms a

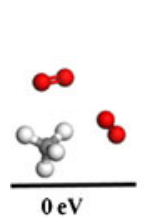

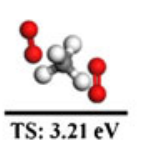

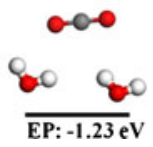

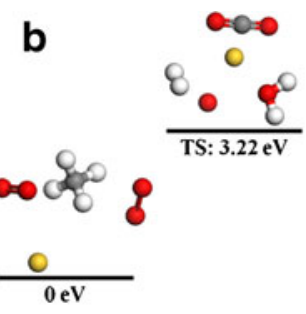

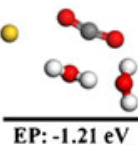

Table 1, the complete oxidation leaves the TS virtually unchanged when the $\mathrm{Au}^{-}$ion catalyst is introduced. However, for the case of the SPO of $\mathrm{CH}_{4}$, reaction (3), the TSs are 4.41 and $3.01 \mathrm{eV}$ in the absence and presence of the $\mathrm{Au}^{-}$ ion catalyst, respectively. So, no barrier reduction is a manifestation of the complete oxidation of $\mathrm{CH}_{4}$. For this case the catalyst has no effect on reaction (1). The obtained results in Table 1 and Figs. 1, 2, 3, 4, 5, 6, and 7 can be understood from three perspectives: resonance scattering theory, thermodynamics consideration, and transition-state calculations.

Resonance scattering approach

Most importantly, when a slow electron collides elastically with atomic $\mathrm{Au}$, a stable negative $\mathrm{Au}^{-}$ion is formed almost exactly at the second deep R-T minimum of the electron elastic scattering TCS of atomic Au [38, 39]. The binding energy of this atomic $\mathrm{Au}^{-}$ion has been determined experimentally to be $2.309 \mathrm{eV}[37,47,48]$. This value also corresponds to the EA of atomic $\mathrm{Au}$. If $\mathrm{CH}_{4}$ is introduced at the second R-T minimum of the electron elastic TCS of atomic $\mathrm{Au}$, it attaches to the $\mathrm{Au}^{-}$ion forming the anionic $\mathrm{Au}^{-}\left(\mathrm{CH}_{4}\right)$ molecular complex [29, 37], with the vertical detachment energy (VDE) of $2.34 \mathrm{eV}$ [29] (incidentally, the R-T minimum is used in the creation of exotic molecules such as RbCs [49, 50]). Here we observe the remarkable characteristic of atomic $\mathrm{Au}$ with respect to $\mathrm{CH}_{4}$, namely the EA of $\mathrm{Au}$ and the VDE of $\mathrm{Au}^{-}\left(\mathrm{CH}_{4}\right)$ are in the second R-T minimum of the $\mathrm{Au}$ elastic TCS. The interaction between the $\mathrm{Au}^{-}$ion and $\mathrm{CH}_{4}$ is comparable to the $\mathrm{C}-\mathrm{H}$ bond strength in $\mathrm{CH}_{4}$ [29]. Thus the $\mathrm{Au}^{-}$ion weakens or disrupts the $\mathrm{C}-\mathrm{H}$ bond in $\mathrm{CH}_{4}$ permitting the formation of $\mathrm{CH}_{3} \mathrm{OH}$ in the presence of $\mathrm{O}_{2}$. We note that the interaction between the $\mathrm{Au}^{-}$ion and $\mathrm{O}_{2}$ is weak [29], showing the inertness of the $\mathrm{Au}^{-}$ion toward $\mathrm{O}_{2}$. After the reaction the $\mathrm{Au}^{-}$ion catalyst is free to catalyze another reaction (the process is similar to the destruction of the ozone by the $\mathrm{Cl}^{-}$ion). This was the determining factor in our selecting the $\mathrm{Au}^{-}$ion as our catalyst. In [29] it has been remarked that the binding energies of the corresponding $\mathrm{Au}$ neutral complexes are significantly less than those of the anion species (for example, the complex $\mathrm{Au}^{-}\left(\mathrm{H}_{2} \mathrm{O}\right)$ has a binding energy that is more than an order of magnitude larger compared with that of the neutral $\mathrm{Au}\left(\mathrm{H}_{2} \mathrm{O}\right)$ complex [29]).

\section{Thermodynamics of reactions}

Low-energy chemical reaction dynamics provides the mechanism for making and breaking bonds. In the $\mathrm{CH}_{4}$ catalysis to $\mathrm{CH}_{3} \mathrm{OH}$ using the atomic $\mathrm{Au}^{-}$ion, the $\mathrm{C}-\mathrm{H}$ bond breaking has been attributed to the formation of the anionic $\mathrm{Au}^{-}\left(\mathrm{CH}_{4}\right)$ molecular complex. The $\mathrm{C}-\mathrm{H}$ bonding has a direct effect on the change in the Gibbs free energy, $G$ $(\Delta G=\Delta H-T \Delta S)$ where $H, T$, and $S$ represent respectively the enthalpy, temperature, and entropy. When the atomic $\mathrm{Au}^{-}$ion is introduced into the oxidation of $\mathrm{CH}_{4}$, the breaking of the $\mathrm{C}-\mathrm{H}$ bonding occurs. Therefore, the system changes from relative order to less order. Hence, the entropy of the system increases, whereas the enthalpy of the system decreases. The overall process results in the Gibbs free energy to be negative, resulting in the spontaneous formation of methanol. To gain a deeper understanding of the process of atomic $\mathrm{Au}^{-}$ion catalysis, the rate of the reaction was calculated using Arrhenius equation [51]. In Figs. 6 and
Fig. 2 Oxidation of methane to carbon monoxide and hydrogen gas in the absence (a) and presence $(\mathbf{b})$ of the $\mathrm{Au}^{-}$ negative ion catalyst. The red, white, gray, and gold spheres represent respectively oxygen, hydrogen, carbon, and gold atoms
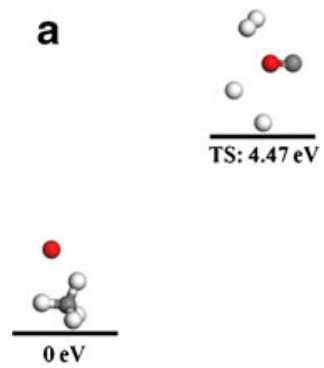
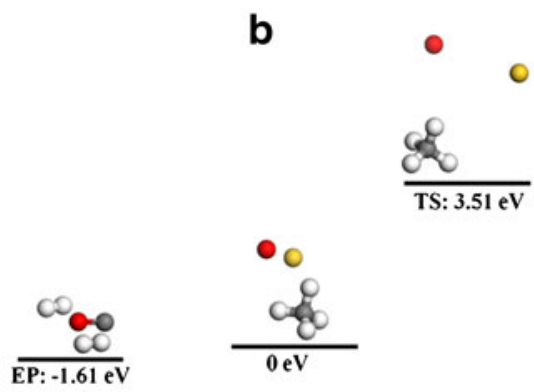
Fig. 3 Oxidation of methane to methanol in the absence (a) and presence $(\mathbf{b})$ of the $\mathrm{Au}^{-}$ negative ion catalyst. The red, white, gray, and gold spheres represent respectively oxygen, hydrogen, carbon, and gold atoms

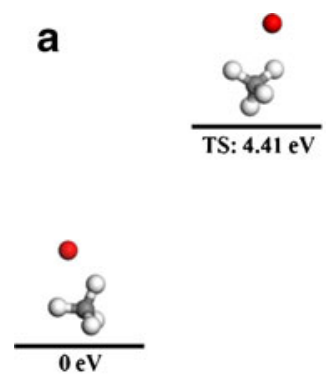

b

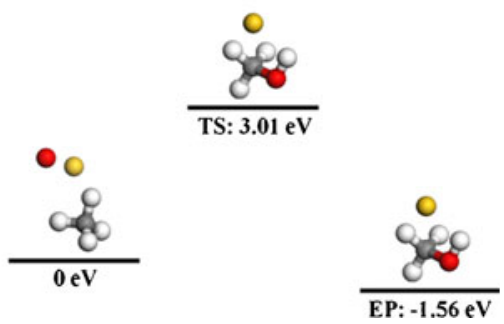

7 , the $\Delta G$ versus $T$ for all the reactions $(1,2,3,4$, and 5$)$ is depicted.

What is remarkable about the effect of the $\mathrm{Au}^{-}$ion catalyst on the SPO of $\mathrm{CH}_{4}$ to $\mathrm{CH}_{3} \mathrm{OH}$ and the complete oxidation of $\mathrm{CH}_{4}$ is that whereas in the absence of the $\mathrm{Au}^{-}$ ion catalyst, the production of methanol is at a much higher temperature (Table 1 and Fig. 7b). However, the introduction of the $\mathrm{Au}^{-}$ion catalyst into the reaction (3) dramatically impacts the rate of the reaction, lowering the temperature at which $\Delta G=0$, from 475 to $325 \mathrm{~K}$ (Table 1 ); this temperature is lower than that for the emission of $\mathrm{CO}_{2}(340 \mathrm{~K})$. Indeed the $\mathrm{Au}^{-}$catalyst is incredibly effective in catalyzing the conversion of $\mathrm{CH}_{4}$ to $\mathrm{CH}_{3} \mathrm{OH}$ without the emission of $\mathrm{CO}_{2}$.

\section{Transition-state calculation}

Figure $1 \mathrm{a}, \mathrm{b}$ presents respectively in the absence and presence of the $\mathrm{Au}^{-}$catalyst the TSs and EPs for the complete oxidation of $\mathrm{CH}_{4}$ to $\mathrm{CO}_{2}$. As already indicated, it is seen from both the figures that the TSs in the absence and presence of the $\mathrm{Au}^{-}$ion catalyst are virtually the same. Also the EPs differ only slightly. These results represent the signature of the complete combustion of $\mathrm{CH}_{4}$. Henceforth, they will be used as the benchmark for assessing the SPO of the various reactions $(1,2,3,4$, and 5).

Figure 2a, b displays the calculated TSs and EPs, in the absence and presence of the $\mathrm{Au}^{-}$ionic catalyst, respectively, for the SPO of $\mathrm{CH}_{4}$ to $\mathrm{CO}+2 \mathrm{H}_{2}$, reaction (2). Without the $\mathrm{Au}^{-}$ionic catalyst, the TS is $4.47 \mathrm{eV}$ (Fig. 2a), while when the $\mathrm{Au}^{-}$ionic catalysts is present the TS drops down to $3.51 \mathrm{eV}$ (Fig. 2b). This is to be expected since the role of the catalyst is to reduce the barrier.
Figure $3 \mathrm{a}, \mathrm{b}$ presents respectively the data without and with the $\mathrm{Au}^{-}$ion catalyst for the $\mathrm{SPO}$ of $\mathrm{CH}_{4}$ to methane, reaction (3). The introduction of the $\mathrm{Au}^{-}$ionic catalyst drops down the TS from $4.41 \mathrm{eV}$ (Fig. 3a) to $3.01 \mathrm{eV}$ (Fig. 3b). We note that this dramatic reduction of the TS of the reaction (3) in the presence of the $\mathrm{Au}^{-}$ion catalyst to a value below that of the complete oxidation of $\mathrm{CH}_{4}$ is the main result of this paper. It represents a significant accomplishment in the field of catalysis using the $\mathrm{Au}^{-}$ion catalyst. The EPs are the same in both Fig. $3 \mathrm{a}, \mathrm{b}$ as expected.

The results for the SPO of $\mathrm{CH}_{4}$ to $\mathrm{H}_{2} \mathrm{CO}+\mathrm{H}_{2} \mathrm{O}$ without and with the $\mathrm{Au}^{-}$ion catalyst are plotted, respectively in Fig. 4a, b. Just as for the reactions (2) and (3), given in Figs. $2 \mathrm{~b}$ and $3 \mathrm{~b}$, the $\mathrm{Au}^{-}$ion catalyst reduces the barrier significantly. However, the TS of $3.29 \mathrm{eV}$ shown in Fig. $4 \mathrm{~b}$ is still slightly higher than that of the complete oxidation of $\mathrm{CH}_{4}$, reaction (1). Perhaps, another atomic negative ion such as $\mathrm{Pd}^{-}$or $\mathrm{Pt}^{-}$[38] added to the $\mathrm{Au}^{-}$ion catalyst could reduce further the TS of $3.29 \mathrm{eV}$ to a value significantly lower than that of the complete oxidation of $\mathrm{CH}_{4}$. We believe that with a combination of the various atomic negative ion catalysts (see for example the various figures in [38]), all the reactions $(2,3,4$, and 5$)$ could be catalyzed directly as in the case of the reaction (3) without $\mathrm{CO}_{2}$ emission. This calls for further investigations.

Figure $5 \mathrm{a}, \mathrm{b}$ contrasts the results for reaction (5), in the absence and presence of the $\mathrm{Au}^{-}$ion catalyst, respectively. Interestingly, for this reaction, the $\mathrm{Au}^{-}$ion catalyst reduces the TS by a small amount, 3.98 versus $3.71 \mathrm{eV}$. As expected, the EP remains unchanged in both figures. Comparing all the results presented in Figs. 1, 2, 3, 4, and 5, it is seen that the $\mathrm{Au}^{-}$ion catalyst has a dramatic effect on reaction (3). Namely, it reduces the TS of the reaction to a value below
Fig. 4 Oxidation of methane to formaldehyde and water in the absence (a) and presence (b) of the $\mathrm{Au}^{-}$negative ion catalyst. The red, white, gray, and gold spheres represent respectively oxygen, hydrogen, carbon, and gold atoms
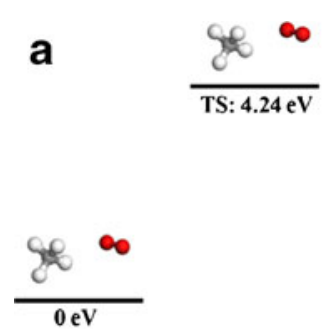
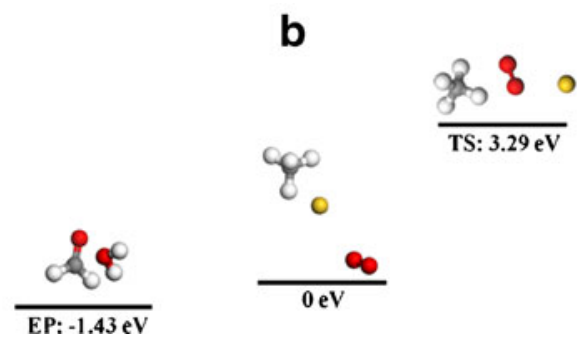

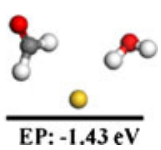


Fig. 5 Oxidation of methane to formic acid and hydrogen gas in the absence (a) and presence (b) of $\mathrm{Au}^{-}$negative ion catalyst.

The red, white, gray, and gold spheres represent respectively oxygen, hydrogen, carbon, and gold atoms a
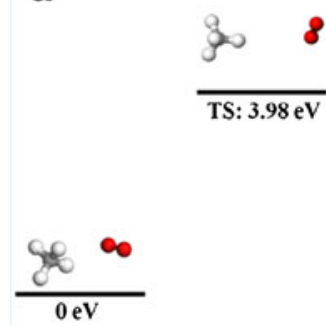

b

$\circ$

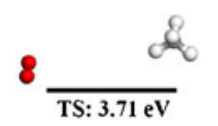

$\circ$

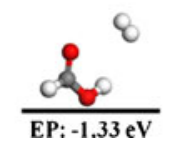

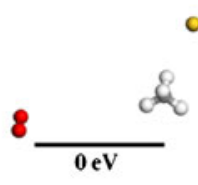

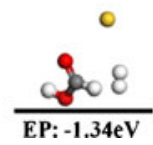

that obtained for the complete oxidation of methane. Hence, our main focus is on reaction (3). The results of these figures are summarized in Table 1.

Figure $6 \mathrm{a}, \mathrm{b}$ presents the results of $\Delta G$ (in electron volts) versus $T$ (in Kelvin) for the reactions (1, 2, 3, 4, and 5). Figure 6 a represents the data in the presence of the $\mathrm{Au}^{-}$ion catalyst, while Fig. $6 \mathrm{~b}$ gives the results in the absence of the catalyst. We focus our discussion on reactions (1) and (3), namely the complete oxidation of $\mathrm{CH}_{4}$ and the production of methanol. Note the position of the curve for the complete oxidation of $\mathrm{CH}_{4}$, represented by the first curve in Fig. 6b, blue circles, and by the second curve in Fig. 6a, blue circles. In Fig. 6b, without the $\mathrm{Au}^{-}$catalyst, the production of the methanol curve occupies the position 4, purple. However, in the presence of the $\mathrm{Au}^{-}$catalyst, curve 4 jumps dramatically to position 1(Fig. 6a) ahead of the $\mathrm{CO}_{2}$ production curve; the temperature at $\Delta G=0$ is $325 \mathrm{~K}$. This can be compared with that of the $\mathrm{CO}_{2}$ production at $340 \mathrm{~K}$. Important here is that the $\mathrm{CO}_{2}$ curve does not change its position from that it occupied in Fig. 6b. This clearly demonstrates the considerable effect the catalyst has on the methanol production. Again this represents the main result of this paper.

Figure $7 \mathrm{a}, \mathrm{b}$ represents respectively the magnification of the data of Fig. 6a, b in the region around $\Delta G=0$; the colors of the curves correspond to those of Fig. 6a, b. These data exhibit clearly the extent to which a reaction has been influenced by the presence of the $\mathrm{Au}^{-}$catalyst. By controlling the temperature around $325 \mathrm{~K}$, methane can be completely oxidized to methanol, rather than to carbon dioxide (see Fig. 7a, first graph), and methanol can further oxidize to formaldehyde and formic acid.
Remarks on the results

As seen from Table 1, the thermodynamics properties agree excellently with the transition-state calculations of the complete and selective partial oxidation of methane. Combustion of methane to carbon dioxide and water in the presence and absence of the $\mathrm{Au}^{-}$ion catalyst yields almost the same transition state. However, for the selective partial oxidation of methane, there is a significant change in the transition states when we compare the results in the presence and absence of the $\mathrm{Au}^{-}$ion catalyst. The introduction of the $\mathrm{Au}^{-}$ion catalyst lowers the transition states for the formation of $\mathrm{CO}, \mathrm{CH}_{3} \mathrm{OH}, \mathrm{H}_{2} \mathrm{CO}$, and $\mathrm{HCO}_{2} \mathrm{H}$ by $21,32,22$, and $7 \%$, respectively. Also when we compare the transition states in the absence of a catalyst for the formation of carbon dioxide and methanol, we clearly see that the TS for the formation of $\mathrm{CO}_{2}$ is smaller than that for the methanol formation. This elucidates why methane undergoes complete oxidation to carbon dioxide, resulting in the increased pollutant emissions. However, if the $\mathrm{Au}^{-}$ion catalyst is used, the oxidation of methane favors the formation of methanol because its TS is lower than that of carbon dioxide. This is much like the separation of a mixture of alcohol and water through the temperature control.

In summary, this proposed catalytic process involving the use of the atomic $\mathrm{Au}^{-}$ion catalyst promises a first and a giant step toward finding and assembling nanocatalysts atom by atom for various chemical reactions, including the direct partial oxidation of methane to useful products without $\mathrm{CO}_{2}$ emission. This will certainly address the problem of greenhouse gas emissions, with considerable impact on the environment.

Table 1 TS, EP, and $T$ represent, respectively, the calculated transition state, energy of the products and temperature of the reaction

\begin{tabular}{|c|c|c|c|c|c|c|}
\hline & $\begin{array}{l}\text { TS }(e V) \\
\text { No catalyst }\end{array}$ & $\begin{array}{l}\mathrm{EP}(\mathrm{eV}) \\
\text { No catalyst }\end{array}$ & $\begin{array}{l}T(\mathrm{~K}) \\
G=0\end{array}$ & $\begin{array}{l}\text { TS }(\mathrm{eV}) \\
\text { Catalyst } \mathrm{Au}^{-}\end{array}$ & $\begin{array}{l}\mathrm{EP}(\mathrm{eV}) \\
\text { Catalyst } \mathrm{Au}^{-}\end{array}$ & $\begin{array}{l}T(\mathrm{~K}) \\
G=0\end{array}$ \\
\hline $\mathrm{CH}_{4}+2 \mathrm{O}_{2} \rightarrow \mathrm{CO}_{2}+2 \mathrm{H}_{2} \mathrm{O}$ & 3.21 & -1.23 & 340 & 3.22 & -1.21 & 340 \\
\hline $\mathrm{CH}_{4}+\frac{1}{2} \mathrm{O}_{2} \rightarrow \mathrm{CO}+2 \mathrm{H}_{2}$ & 4.47 & -1.61 & 500 & 3.51 & -1.60 & 375 \\
\hline $\mathrm{CH}_{4}+\frac{1}{2} \mathrm{O}_{2} \rightarrow \mathrm{CH}_{3} \mathrm{OH}$ & 4.41 & -1.56 & 475 & 3.01 & -1.56 & 325 \\
\hline $\mathrm{CH}_{4}+\mathrm{O}_{2} \rightarrow \mathrm{H}_{2} \mathrm{CO}+\mathrm{H}_{2} \mathrm{O}$ & 4.24 & -1.42 & 450 & 3.29 & -1.43 & 350 \\
\hline $\mathrm{CH}_{4}+\mathrm{O}_{2} \rightarrow \mathrm{HCO}_{2} \mathrm{H}+\mathrm{H}_{2}$ & 3.98 & -1.33 & 425 & 3.71 & -1.34 & 400 \\
\hline
\end{tabular}




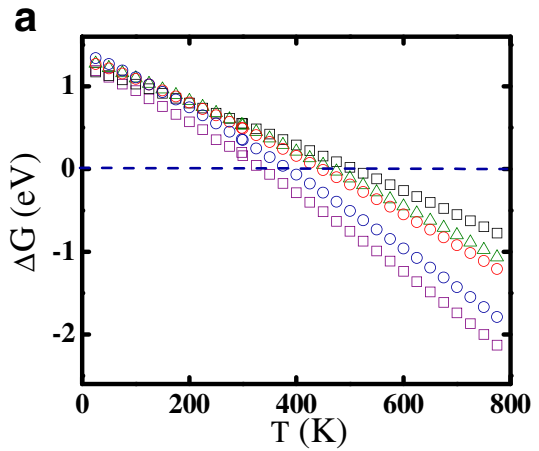

Fig. 6 a Change in the Gibbs free energy (in electron volts) versus temperature, $T$ (in Kelvin), in the presence of the $\mathrm{Au}^{-}$ion catalyst. The first (purple squares), second (blue circles), third (red circles), fourth (green triangles), and fifth (black squares) curves correspond respectively to the reactions leading to the production of $\mathrm{CH}_{3} \mathrm{OH}, \mathrm{CO}_{2}$, $\mathrm{H}_{2} \mathrm{CO}, \mathrm{CO}$, and $\mathrm{HCO}_{2} \mathrm{H}$ beyond the optimum temperatures. b Change

\section{Discussion of results}

Nanoparticles are essentially a small cluster of atoms; here we are dealing with a single atom (more specifically, its negative ion). The origin of the catalytic activity of supported gold nanoparticles is still not fully understood [52]. Turner et al. [52] investigated the catalytic behavior of very small size (approximately $1.4 \mathrm{~nm}$ ) gold nanoparticles obtained from atomic gold clusters. They speculated that the remarkable catalytic behavior of the atomic nanoparticles was due partly to the strong electronic interaction between the gold and the titanium dioxide support. Here we use atomic gold and atomic gold anion, such as used in the experiment of Zheng et al. [37], which are obtained from laser-ablated gold foil. This completely avoids any complication associated with the support. In $[6,7]$ we have used a similar analysis to understand the experiments $[4,5]$ on the catalysis of $\mathrm{H}_{2} \mathrm{O}_{2}$ from $\mathrm{H}_{2} \mathrm{O}$ using $\mathrm{Au}$ and $\mathrm{Pd}$ nanoparticles.

This investigation could also help toward understanding the issue of the support since our approach uses simply atoms and atomic anions. As pointed out in [6,7], our approach worked for the catalysis of $\mathrm{H}_{2} \mathrm{O}$ to $\mathrm{H}_{2} \mathrm{O}_{2}$ using the atomic $\mathrm{Au}^{-}$catalyst for the reasons: the large EA of atomic $\mathrm{Au}$, the presence of the second deep R-T minimum

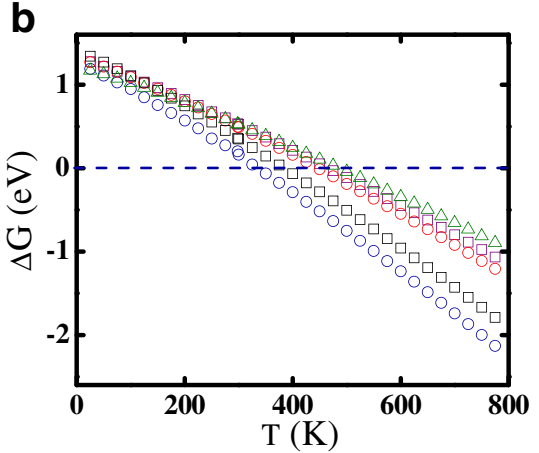

in the Gibbs free energy (in electron volts) versus temperature, $T$ (in Kelvin), in the absence of the $\mathrm{Au}^{-}$ion catalyst. The first (blue circles), second (black squares), third (red circles), fourth (purple squares), and fifth (green triangles) curves correspond respectively to the reactions leading to the production of $\mathrm{CO}_{2}, \mathrm{HCO}_{2} \mathrm{H}, \mathrm{H}_{2} \mathrm{CO}, \mathrm{CH}_{3} \mathrm{OH}$, and $\mathrm{CO}$ beyond the optimum temperatures

in the electron elastic scattering TCS for atomic $\mathrm{Au}$, and the existence of the VDE for the anionic $\mathrm{Au}^{-}\left(\mathrm{H}_{2} \mathrm{O}\right)$ complex within this R-T minimum. For $\mathrm{CH}_{4}$ catalysis the first two conditions still hold. However, the VDE (2.34 eV [37]) of the anionic $\mathrm{Au}^{-}\left(\mathrm{CH}_{4}\right)$ complex is still within this second R-T minimum of the Au elastic TCS. To get a sense of how the proposed mechanism might be affected when small clusters are used rather than the atoms, we recently used density functional theory to investigate the structure and dynamics of small clusters of 2, 3, 4, and $5 \mathrm{Pt}$ atoms [53]; the geometric optimization was achieved using the DMol package under the generalized gradient approximation with the Perdew-Wang exchange correlation functional [42].

The electron affinities for the clusters were evaluated and compared with measurement and other theoretical calculations. Our calculated EAs were found to be closer to the measurement, demonstrating the importance of careful geometric optimization of the structures. Furthermore, the EAs for the clusters did not deviate significantly from that of the atom. This implies that the proposed mechanism would still be applicable to small clusters. However, we do not know yet how far this would hold as the cluster size is increased beyond 5. Importantly, Hakkinen et al. [54] investigated the VDE for $\mathrm{Au}_{7}{ }^{-}$; they found that the calculated VDE varied
Fig. 7 a Same as Fig. 6a, except that here we show the expanded region $-0.50 \mathrm{eV} \leq \Delta G \leq 0.50 \mathrm{eV}$. b Same as Fig. 6b, except that here we show the expanded region $-0.50 \mathrm{eV} \leq \Delta G \leq 0.50 \mathrm{eV}$. The same color scheme used for both Figures 6 and 7
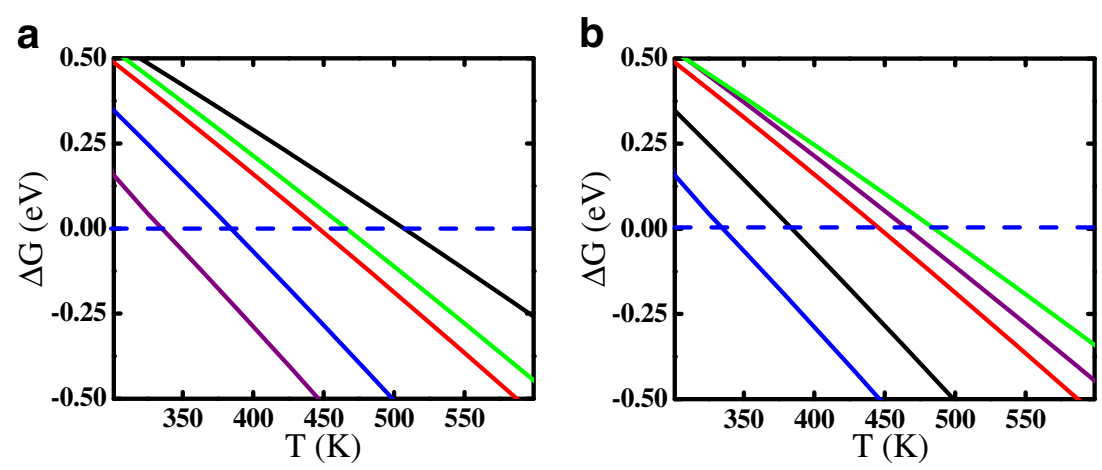
between 2.75 and $3.57 \mathrm{eV}$, with their value being $3.46 \mathrm{eV}$ which agrees well with the experimental value of $3.5 \mathrm{eV}$ cited in [54]. Even for a cluster of this size, our analysis would work because the VDE of $\mathrm{Au}_{7}{ }^{-}$is still within the effective range of the second R-T minimum of the Au elastic TCS $[6,7]$. To firm this, we would need to calculate the electron elastic TCS for the $\mathrm{Au}_{7}$ cluster and identify the R-T minimum and the various resonances [38]. This will certainly be one of our future research projects.

Finally, the present paper could also lead to a better understanding of the role of the noble metal particle $(\mathrm{Au})$ size and the $\mathrm{TiO}_{2}$ polymorph in the catalytic production of $\mathrm{H}_{2}$ from ethanol [55]. Notably, Au nanoparticles of size in the range 3$12 \mathrm{~nm}$ were found to be particularly photoreactive.

\section{Conclusion}

The atomic $\mathrm{Au}^{-}$ion catalyst is found to reduce the optimum temperature for the SPO of methane to about $325 \mathrm{~K}$ for $\mathrm{CH}_{3} \mathrm{OH}$ production. Consequently, in the presence of the atomic $\mathrm{Au}^{-}$ion catalyst, by controlling the temperature around $325 \mathrm{~K}$, methane can be completely oxidized to methanol without the emission of the $\mathrm{CO}_{2}$, thereby broadening considerably the scope of gold's applications. Using the $\mathrm{Au}^{-}$ ion as the catalyst essentially disrupts the $\mathrm{C}-\mathrm{H}$ bonding in $\mathrm{CH}_{4}$ oxidation through the ionic $\mathrm{Au}^{-}\left(\mathrm{CH}_{4}\right)$ molecular formation, thereby eliminating the competition from the carbon dioxide formation. We conclude by recommending that the negative ions of the atoms such as those in [38] be investigated individually or in combinations for possible catalytic activities in the selective partial oxidation of methane; the $\mathrm{Pt}^{-}$negative ion will accomplish similar results as the $\mathrm{Au}^{-}$ion catalyst.

Acknowledgments AZM is grateful to Professor Maaza for introducing him to nanogold and nanoplatinum catalysis while visiting iThemba Labs, South Africa. Research was supported by Army Research Office (Grant W911NF-11-1-0194), U.S. DOE Office of Science, AFOSR (Grants FA9550-10-1-0254 and FA9550-09-1-0672), and CAU CFNM, NSF-CREST Program.

Open Access This article is distributed under the terms of the Creative Commons Attribution License which permits any use, distribution and reproduction in any medium, provided the original author(s) and source are credited.

\section{References}

1. Beecy DJ, Ferrell FM, and Carey JK (2001) In Proceedings of 1st National Conference on Carbon Sequestration, May 14-17

2. Song CS (2006) Global challenges and strategies for control, conversion and utilization of $\mathrm{CO}_{2}$ for sustainable development involving energy, catalysis, adsorption and chemical processing. Catal Today 115:2-32
3. Armour EAG (2010) J Phys Conference Series 225:012002 and references therein

4. Edwards JK, Carley AF, Herzing AA, Kiely CJ, Hutchings GJ (2008) J Chem Soc Faraday Discuss 138:225

5. Edwards JK, Solsona B, Landon P, Carley AF, Herzing A, Watanabe M, Kiely CJ, Hutchings GJ (2005) J Mater Chem 15:4595

6. Msezane AZ, Felfli Z, Sokolovski D (2010) J Phys B 43:201001

7. Msezane AZ, Felfli Z, Sokolovski D (2010) Europhys News 41:11

8. Tesfamichael A, Suggs K, Felfli Z, Wang X-Q, Msezane AZ (2012) arXiv:1201.2191v1

9. Haruta M (1997) Catal Today 36:153

10. Dumur F, Guerlin A, Dumas E, Bertin D, Gigmes D, Mayer CR (2011) Gold Bull 44:119, and references therein

11. Sanchez A, Abbet S, Heiz U, Schneider WD, Hakkinen H, Barnett RN, Landman U (1999) J Phys Chem A 103:9573

12. Bernhardt TM, Heiz U, Landman U (2007) Chemical and catalytic properties of size-selected free and supported clusters. In: Heiz U, Landman U (eds) Nanocatalysis (nanoscience and technology). Springer, Berlin, pp 1-244

13. Gorin DJ, Toste FD (2007) Nature 446:395

14. Moshfegh AZ (2009) J Phys D 42:233001

15. Beltrán MR, Suárez Raspopov R, González G (2011) Eur Phys J D $65: 411$

16. Thompson DT (2007) Nano Today 2:40

17. Bond GC, Louis C, Thompson DT (2006) In: Hutchings J (ed) Catalysis by gold catalytic science series. Imperial College Press, London

18. Lim D-C, Hwang C-C, Ganteför G, Kim YD (2010) Model catalysts of supported $\mathrm{Au}$ nanoparticles and mass-selected clusters. Phys Chem Chem Phys 12:15172

19. van Bokhoven JA (2009) Chimia 63:25

20. Daniel M-C, Astruc D (2004) Chem Rev 104:293

21. Hashmi ASK, Hutchings GJ (2006) Gold catalysis. Angew Chem Int Ed 45:7896

22. Hashmi ASK (2007) Gold-catalyzed organic reactions. Chem Rev 107:3180

23. Jurgens B, Kubel C, Schulz C, Nowitzki T, Zielasek V, Bienrt J, Biener MM, Hamza AV, Baumer M (2007) Gold Bull 40(2):142

24. Kimble ML, Castleman AW Jr, Mitric R, Burgel C, BonacicKoutecky V (2004) J Am Chem Soc 126:2526

25. Liu Y-C, Lin L-H, Chiu W-H (2004) J Phys Chem B 108:19237

26. González Orive A et al (2011) Nanoscale 3:1708

27. Wong MS, Alvarez PJJ, Fang YL, Akcin N, Nutt MO, Miller JT, Heck KN (2009) J Chem Tech Biotech 84:158

28. Pretzer LA, Nguyen QX, Wong MS (2010) J Phys Chem C $114: 21226$

29. Gao Y, Huang W, Woodford J, Wang L-S, Zeng XC (2009) J Am Chem Soc 131:9484

30. Sorokin B, Kudrik EV, Bouchu D (2008) Chem Technol 5:T43

31. Vafajoo L, Sohrabi M and Fattahi M (2011) World Academy of Science, Engineering and Technology 73:797

32. Mohr F (ed) (2009) Gold chemistry, applications and future directions in the life sciences. Wiley, New York

33. Yuan J, Wang L, Wang Y (2011) Ind Eng Chem Res 50(10):6513

34. Chen W et al (2009) Catal Today 140:157

35. Zhang Q, He D, Zhu Q (2008) J Nat Gas Chem 17:24

36. Lang SM, Bernhardt TM, Barnett RN, Landman U (2011) J Phys Chem C 115:6788

37. Zheng W, Li X, Eustis S, Grubisic A, Thomas O, De Clercq H, Bowen K (2007) Chem Phys Lett 444:232

38. Felfli Z, Msezane AZ, Sokolovski D (2011) J Phys B 44:135204

39. Felfli Z, Eure AR, Msezane AZ, Sokolovski D (2010) NIMB 268:1370

40. Tkatchenko A, Scheffler M (2009) Phys Rev Lett 102:073005

41. Perdew JP, Burke K, Ernzerhof M (1996) Phys Rev Lett 77:3865

42. DMol3 (2011) Accelrys Software Inc., San Diego 
43. Suggs K, Reuven D, Wang X-Q (2011) J Phys Chem C 115:3313

44. Suggs K, Person V, Wang X-Q (2011) Nanoscale 3:2465

45. Samarakoon D, Chen Z, Nicolas C, Wang X-Q (2011) Small 7:965

46. Nam LTH, Dat VT, Loan NTT, Radnik J, Roduner E (2010) J Chem 48:149

47. Hotop H, Lineberger WC (1985) J Phys Chem Ref Data 14:731

48. Andersen T, Haugen HK, Hotop H (1999) J Phys Chem Ref Data 28:1511

49. Simoni A, Launay JM, Soldan P (2009) arXiv:0901.3129v1

50. Balakrishnan N, Quéméner G, Dalgarno A (2009) Inelastic collisions and chemical reactions of molecules at ultracold temperatures. In: Stwalley WC, Krems RV, Friedrich B (eds) Cold molecules: theory, experiment, applications. CRC Press, Boca Raton, Florida

51. Levine RD (2005) Molecular reaction dynamics. Cambridge University Press, Cambridge

52. Turner M, Golovko VB, Vaughan OPH, Abdulkin P, BerenguerMurcia A, Tikhov MS, Johnson BFG, Lambert RM (2008) Nature 454:981

53. Chen Z, Msezane AZ (2010) Density functional theory investigation of small Pt clusters. Bull Am Phys Soc 55(57)

54. Hakkinen H, Moseler M, Landman U (2002) Phys Rev 89:033401

55. Murdoch M, Waterhouse GIN, Nadeem MA, Metson JB, Keane MA, Howe RF, Llorca J, Idriss H (2011) Nat Chem 3:489 